\title{
Emerging infectious disease selects for darker plumage coloration in greenfinches
}

\author{
Marju Männiste and Peeter Hõrak* \\ Department of Zoology, Institute of Ecology and Earth Sciences, Tartu University, Tartu, Estonia
}

\section{Edited by:}

Geoffrey E. Hill, Auburn University, USA

\section{Reviewed by:}

Emilie Snell-Rood, University of Minnesota, USA

Keith Tarvin, Oberlin College, USA

\section{${ }^{*}$ Correspondence:}

Peeter Hõrak, Department of Zoology, Institute of Ecology and Earth Sciences, Tartu University, Vanemuise 46, 51014 Tartu, Estonia e-mail: horak@ut.ee
Outbreaks of emerging infectious disease offer a unique chance to study viability selection in action in short time windows. Finch trichomonosis, caused by a protozoan Trichomonas gallinae emerged in Great Britain in 2005 and led to epidemic mortality and a significant population decline of greenfinches, Carduelis chloris in UK and Northern European countries in subsequent years. We recorded covariation between plumage characteristics and trichomonosis-induced mortality among wild-caught greenfinches brought into captivity in Tartu, Estonia. Occurrence of fault bars (markers of stressful conditions experienced during feather growth) on tail feathers was five times higher among the dead birds than among survivors. Black (eumelanotic) compartments of tail feathers of survivors were on average $22 \%$ darker than feathers of dead birds. Such pattern is best explained by proposed pleiotropic effects of genes involved in eumelanin production on immune function. These findings suggest that melanin-based coloration can evolve via mechanisms that are independent of visual information provided by the pigment.

Keywords: emerging infectious disease, eumelanin, fault bars, pleiotropy, plumage coloration, Trichomonas gallinae

\section{INTRODUCTION}

Parasites, including infectious diseases can be arguably considered as a major source of mortality in wild animal populations (Lochmiller and Deerenberg, 2000). Parasites can kill their hosts directly or, probably more often, via collateral damage resulting from launching immune responses (Graham et al., 2005). Mounting anti-parasite defenses can also deplete hosts' energy reserves and other maintenance resources, making them vulnerable to predation (Møller and Erritzøe, 2000) or effects of harsh environmental conditions (Moret and Schmid-Hempel, 2000). Hosts differ in their vulnerability to infections and these differences may be mirrored in their appearance. Detection of cues predicting morbidity and mortality is an essential task for both medical diagnosis and evolutionary ecologists aiming at explaining causes and consequences of phenotypic variation in animals.

Color and morphology of feathers provide ample cues about the physiological condition of individual birds during feather growth. For instance, most common feather pigments-melanins and carotenoids - can be indicative of the individuals' developmental and hormonal milieu, their ability to find and process specific micronutrients and of immunological and oxidative challenges experienced during feather growth (reviewed by Hill, 2006; McGraw, 2006a,b; Jacquin et al., 2013; Walker et al., 2013). Additional information about the individuals' state during feather growth is provided by the physical properties of the feathers such as different parameters of size and structure (e.g., Desrochers et al., 2009). All these parameters have a potential to impinge on fitness either by viability selection, affecting thermoregulatory and aerial performance and crypsis (reviewed by Bortolotti,
2006) or by signal selection conveying information about individual quality in inter- and intrasexual selection and other social contexts (reviewed in Hill and McGraw, 2006; McGraw, 2008; Svensson and Wong, 2011).

Because of ubiquitous selection pressure generated by parasites and due to tight integration of the immune system with almost any physiological function of an organism, plumage characteristics have been long thought to reveal individual's ability to deal successfully with infections (Hamilton and Zuk, 1982; Lozano, 1994; Moreno and Møller, 2006; Simons et al., 2012). However, despite the relatively well-documented evidence about covariation between feather characteristics and survival (see Jennions et al., 2001; Roulin and Altwegg, 2007; Saino et al., 2013b), the number of studies documenting direct associations between plumage characteristics and infection-induced mortality or morbidity is limited. The majority of examples involve carotenoidbased ornametal feather coloration: Nolan et al. (1998) showed that male house finches (Haemorhous mexicanus) that survived Mycoplasma gallisepticum outbreak had significantly redder plumage than males that did not survive. Hill and Farmer (2005) later demonstrated on the same species that males with redder plumage cleared Mycoplasma infection significantly better than did males with yellower plumage. Similarly, the area of yellow carotenoid-based tail patch in male greenfinches (Carduelis chloris) predicted the rate of clearance of experimental Sindbis virus infection (Lindström and Lundström, 2000). Contrary to these findings, Van Oort and Dawson (2005) found that male redpolls (Carduelis flammea) with larger and redder plumage patches were less likely to survive salmonellosis epidemics than males with less developed carotenoid signals. A single study that examined 
the epidemic survival in relation to melanin-based ornaments detected a selection against the most ornamented males too. Western bluebirds (Sialia mexicana) that died in an outbreak of enteritis (with unidentified source) were significantly more highly ornamented (with darker, redder melanin-based breast patches) than males that survived (Keyser and Siefferman, 2005).

Here we report about associations between plumage characteristics and trichomonosis-induced mortality in wild-caught greenfinches in captivity. Trichomonosis is a disease caused by the flagellate protozoan parasite Trichomonas gallinae, which is well known historically in pigeons and raptors and can cause high mortality. The parasite inhabits the upper digestive tract of the bird and spreads through saliva. It causes necrotic inflammation of the oropharynx that eventually inhibits swallowing and leads to starvation and dehydration (Atkinson et al., 2008). Since 2005, the epidemics of trichomonosis in fringillid birds spread rapidly from UK to Northern Europe. The spread of epidemics coincided with $47 \%$ of reduction of breeding greenfinch population in Southern Finland between 2009 and 2010 (Lehikoinen et al., 2013). Since winter 2009, reports on dead and debilitated greenfinches with symptoms of trichomonosis at bird tables have been occasionally reported in Estonian newspapers. In January 2013, we captured 46 female greenfinches for a behavioral study in Tartu, SouthEast Estonia. Five of these birds died during the first 11 days spent in captivity with symptoms of trichomonosis. This gave us a unique opportunity to study associations between plumage characteristics and trichomonosis-induced mortality. We measured the melanin-based coloration of outermost tail feathers, as well as three parameters of feather size that are sensitive to stressors experienced during feather growth in greenfinches (Männiste and Hõrak, 2011). Additionally we asked whether mortality can be predicted by an occurrence of fault bars - translucent areas across feathers grown under stressful conditions - that have been associated with increased mortality in different bird species (Bortolotti et al., 2002; Møller et al., 2009).

\section{MATERIALS AND METHODS}

Forty six female wild greenfinches were captured with mist-nets at bird feeders in a garden in the city of Tartu, Estonia $\left(58^{\circ} 22^{\prime}\right.$ $\mathrm{N} ; 26^{\circ} 43^{\prime} \mathrm{E}$ ) on 7 th, 8 th, 14 th, and 15 th January 2013 . The birds were aged (yearlings vs. older) according to Svensson (1992). The birds were housed indoors in individual cages $(27 \times 51 \times 55 \mathrm{~cm})$ with sand-covered floors in a single room where they had visual contact with their neighbors. The average temperature in the aviary during the study was $13.4 \pm 1.3^{\circ} \mathrm{C}$. The birds were supplied ad libitum with sunflower seeds and tap water and were exposed to a natural day-length cycle using artificial lighting by luminophore tubes. Survivors were released back to their natural habitat on 11th of March 2013. The study was conducted under license from the Estonian Ministry of the Environment (License \# 1-4.1/11/100, issued on 23rd March 2011), and was approved by the Committee of Animal Experiments at the Estonian Ministry of Agriculture (decision \# 95, issued on 17th January 2012).

The left outermost tail feather was plucked from all of the birds being alive on 18th January as well as from the dead birds dying before that date. Reflectance of the feathers was measured spectrophotometrically (avoiding areas with fault bars) as described previously by Hõrak et al. (2010). We report the summed reflectance in the bird-visible part of the spectrum $(326-700 \mathrm{~nm})$. Measures of reflectance in the UV-compartment of the spectrum $(326-400 \mathrm{~nm})$ and visible compartment $(400-700 \mathrm{~nm})$ correlated strongly $(r=0.79, P<$ $0.0001, n=43)$. Repeatabilities of the triplicate measurements were $0.97\left[F_{(2,40)}=74.2, P<0.0001\right]$ for inner vane and 0.91 $\left[F_{(2,40)}=74.2, P<0.0001\right]$ for outer vane, respectively. All six measurements were averaged into single parameter of reflectance. Feather mass, length and rachis diameter were recorded as in previous study by Männiste and Hõrak (2011). Occurrence of fault bars (Figure 1C) was recorded by careful visual inspection of feathers by a single observer (MM).

Studied metric variables of dead birds and survivors were normally distributed and were compared with t-tests. Proportions were compared with $\chi^{2}$-tests with Yates correction. In order to test for the simultaneous effects of occurrence of fault bars and feather coloration on mortality, logistic regression was applied (PROC CATMOD, SAS/ STAT version 9.2, SAS Institute Inc., Cary, NC). The fit of model to the data was checked with likelihood ratio test, which indicated good fit $(P=0.99)$. Means are reported with $\pm \mathrm{SD}$. All tests are two-tailed with a P-level below 0.05 as a criterion for significance. Sample sizes for survivors differ between different tests due to our inability to record all feather parameters from all the birds.

\section{RESULTS}

Altogether five birds (11\% of captured ones) died during the first 5-11 days spent in captivity: two on the 5th day, one on the 6th, 8 th, and 11 th day. Dead birds had lost on average $13.5 \mathrm{~g}(42 \%)$ of their body mass at capture. Body mass of corpses ranged from 15.4 to $19.5 \mathrm{~g}$, (average: $18.5 \pm 1.6 \mathrm{~g}$ ). Surviving birds weighed on average $37 \%$ more than the dead ones in their first week of captivity $(29.5 \pm 2.2 \mathrm{~g}, n=41)$.

Clear symptoms of trichomonosis were detected on necropsies of three birds of five (see appendix S1 in the electronic supplementary material). Symptoms included yellowish mass (necrotic ingluvitis) surrounding the oesophagus (Robinson et al., 2010) and un-swallowed seeds in it (Neimanis et al., 2010). Two birds did not show symptoms of ingluvitis but their patterns of mass loss and general appearance (muscular hypertrophy, absence of subcutaneous fat reserves) were similar to three clearly diagnosed individuals.

Dead birds and survivors had similar age composition, mass at capture and parameters of feather size (Table 1). Feathers of survivors were on average $22 \%$ (1.5 SD units of the whole sample) darker than feathers of dead birds (Table 1, Figure 1). This difference remained significant when we restricted our comparisons to three birds with clear symptoms of trichomonosis. Among three dead birds with clear symptoms of trichomonosis the reflectance of feathers was $3492 \pm 304$ and among 38 survivors the reflectance was $2757 \pm 456(t=2.73, P=0.010)$. Prevalence of fault bars was five times higher among the feathers of dead birds than among survivors (Table 1).

Because both occurrence of fault bars and feather color appeared to indicate viability of birds, we also tested whether 


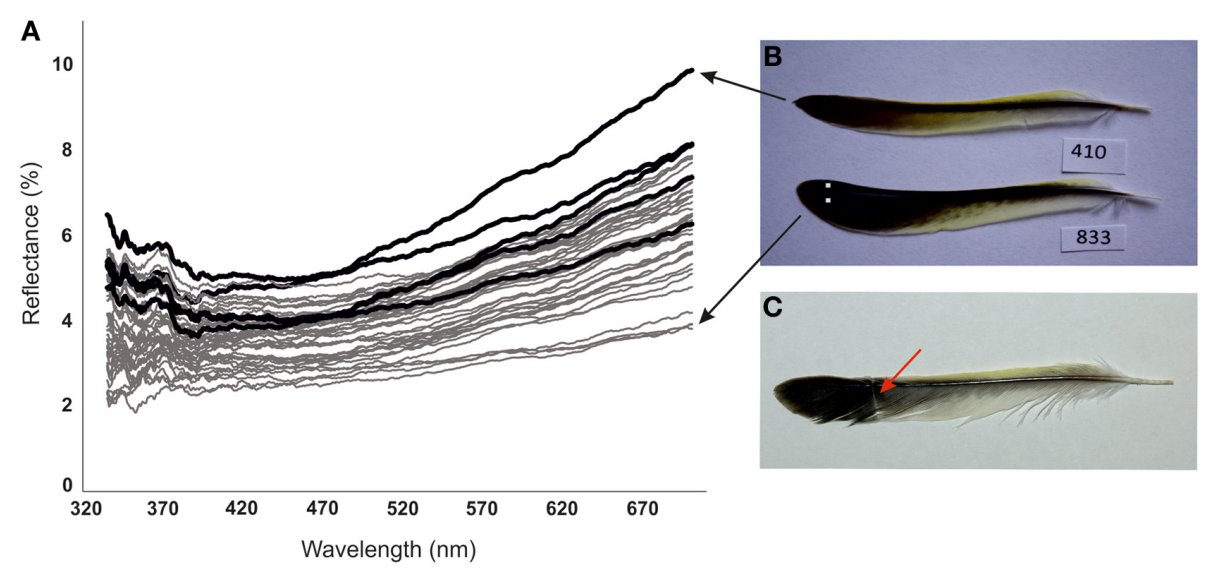

FIGURE 1 | (A) Reflectance spectra of tail feathers of female greenfinches surviving (gray lines) and dying (black lines) in the outbreak of trichomonosis. (B) Palest and darkest extremes of measured feathers. White dots indicate locations of color measurement. (C) Tail feather of female greenfinch with fault bar, indicated by an arrow.

Table 1 | Comparison of greenfinches that did and did not survive trichomonosis outbreak.

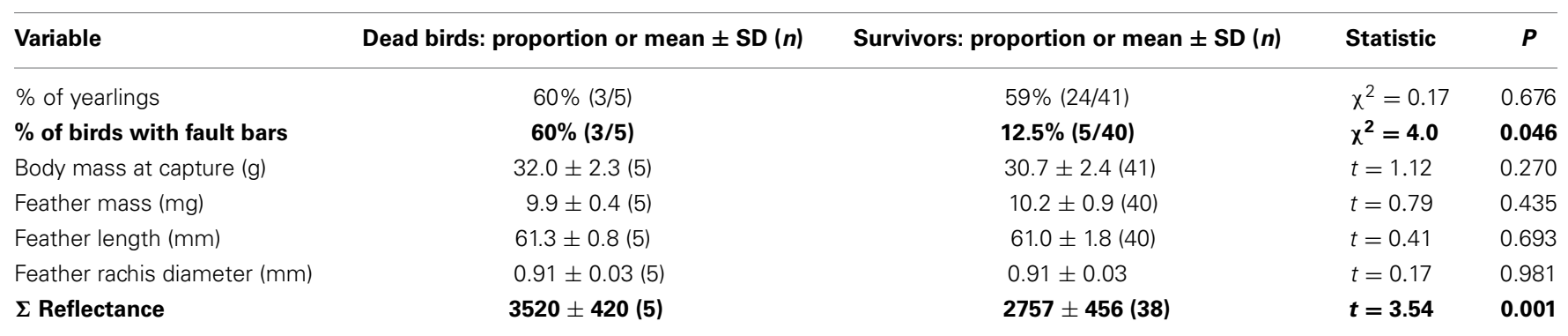

$\%$ of yearlings is a proportion of the birds born in preceding spring/summer as compared to older individuals. \% of birds with fault bars is a proportion of individuals

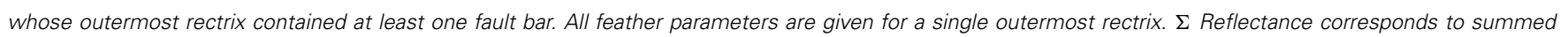
reflectance in spectral segments of $326-700 \mathrm{~nm} . \chi^{2}$ statistic is calculated with Yates correction. Significant differences are indicated in bold.

those traits covary. This was indeed the case. Feathers of birds with fault bars had $14 \%$ higher reflectance $(3220 \pm 534, n=8)$ than feathers without fault bars $(2760 \pm 473, n=35, t=2.43$, $P=0.020)$. Entering the occurrence of fault bars and plumage reflectance simultaneously into the model of logistic regression predicting mortality indicated that feather color was better predictor of mortality than occurrence of fault bars $\left(\chi_{(1,40)}^{2}=\right.$ $3.9, P=0.047$ for reflectance and $\chi_{(1,40)}^{2}=1.1, P=0.303$ for fault bars).

\section{DISCUSSION}

Outbreaks of emerging infectious disease offer a unique chance to study viability selection in action in short time windows. Trichomonosis has been responsible for massive (35\%) decline in breeding greenfinch numbers in UK in 2006 (Robinson et al., 2010) and in Finland in 2009 (47\%) with a smaller (20\%) but still impressive effect on greenfinches in Sweden (Lehikoinen et al., 2013). Given the extreme pathogenicity and recent emergence of trichomonosis in greenfinches, it has been suggested that infection may have recently spilled over from another host species, leaving little time for host adaptations to evolve (Neimanis et al., 2010).
Mortality among the captured birds was $11 \%$. Unfortunately we don't know whether any (or what proportion) of the surviving birds also were infected with Trichomonas but healed in captivity or were resistant carriers of the parasite. However, indirect evidence suggests that true prevalence of the infection might have been actually higher than $11 \%$. For instance, the average mass of dead birds (18.5 g) in our aviary was $13 \%$ lower than that of average greenfinches found dead during trichomonosis outbreak in Finland (21.3 g) (Lehikoinen et al., 2013). The most likely explanation for such a difference is that our aviary environment with an average temperature of $13.4^{\circ} \mathrm{C}$ appeared unnaturally favorable for the birds as compared to northern winter conditions. We thus suspect that only the birds with weakest immune systems (or improper responses) died of trichomonosis while others (that would have normally died under natural conditions) managed to control their infections in the aviary. We believe that design of our study appeared especially powerful for detecting the selection on plumage coloration because the mortality occurred under controlled conditions in the aviary. For instance, one might expect that diseased individuals are especially vulnerable to predation in the wild (Møller and Erritzøe, 2000). Collecting the available corpses of dead individuals 
that are not depredated in the wild thus inevitably leads to sampling bias.

Fault bars are developmental irregularities in feathers that result from a variety of stresses (nutritional, weather-induced, psychological) that occur during feather growth (Bortolotti et al., 2002; Møller et al., 2009). Molt in greenfinches occurs from late July to early November (Cramp and Perrins, 1994) and the growth period of retrices lasts about 50 days (Hõrak et al., 2013). High prevalence of fault bars in dead finches thus suggests that those individuals either experienced more stressors or appeared more susceptible to stress already in the preceding autumn. Thus, it seems unlikely that Trichomonas caused fault bars in the finches, but instead, birds that were more stressed during the autumn molt appear to be more susceptible to Trichomonas in winter. The relationship between fault bars and mortality described in the present study is different from that suggested by other studies. For instance, Møller et al. (2009) demonstrated that prey items of the goshawk (Accipiter gentilis) in Denmark had nearly three times higher occurrence of fault bars than the general population of different prey species. Possible mechanism involves decrease of aerial performance of prey due to breakage of feathers at fault bars. Although our findings corroborate the diagnostic value of fault bars in predicting mortality as found in other studies (Bortolotti et al., 2002; Møller et al., 2009), our study shows that reduction of aerial performance is not the only mechanism connecting occurrence of fault bars with mortality. Notably, fault bars and feather size parameters seem to convey different information about the stressful experiences during feather growth. Administration of stress hormone and induction of immune response by a plant toxin phytohaemagglutinin hinder feather growth in greenfinches (Männiste and Horrak, 2011). However, none of the three measured parameters of feather size was associated with mortality in the current study.

This study is the first one to detect trichomonosis-induced viability selection on plumage characteristics. Detection of extremely strong selection for lower plumage reflectance is particularly interesting. Assuming non-zero heritability for tail feather coloration, one would predict that the recent outbreak of trichomonosis leads to evolution of darker melanin-based coloration in greenfinches and may-be other new host species of trichomonosis. This hypothesis can be tested by comparison of plumage coloration of greenfinches surviving population crashes (e.g., after 2006 in UK and after 2009 in Finland) with museum specimens collected before the mass emergence of trichomonosis in fringillid birds. Coloration of dark areas of tail feathers in greenfinches is determined by eumelanin (Hõrak et al., 2010). Heritability of melanin-based plumage reflectance has been seldom reported. One of the few such studies (Saino et al., 2013c) found high values $\left(h^{2}=0.8\right)$ for both visible and UV components of coloration (a mixture of pheo- and eumelanin) of throat feathers in barn swallows (Hirundo rustica). It should be recalled, however, that remarkable externally induced variation in melanin-based coloration is also well documented (reviewed by McGraw, 2006b), so that the rate of evolution of darker coloration in response to trichomonosis epidemic is currently difficult to predict.
Why were the greenfinches with higher plumage reflectance selected against? One hypothetical explanation would be that paler females appear more exposed to contaminated food or water sources due to some dominance-related behavioral mechanism. Such mechanism was proposed for explaining why male redpolls with larger and redder plumage patches experienced highest mortality in salmonellosis epidemics. Van Oort and Dawson (2005) suggested that if carotenoid ornamentation in redpolls functions as a status badge of dominance, bright males would have had priority access to highly preferred, and contaminated, food patches. Similarly to salmonellosis in redpolls, trichomonosis spreads at shared feeding places such as bird tables (Neimanis et al., 2010). However, it is currently unknown weather the color of black tips of the retrices in female greenfinches is related to their dominance status or exposure to contaminated feeding sites.

An alternative explanation for the trichomonosis-induced selection on plumage coloration involves covariation between melanin-based coloration and some relevant aspect of immune function. Accumulating evidence indicates that melanin-based coloration is often correlated with other physiological, morphological and behavioral traits as an outcome of pleiotropic effects of the key regulators of melanogenesis (Ducrest et al., 2008; Gangoso et al., 2011). For example, the pro-opiomelanocortin (POMC) gene encodes for melanocortin peptide hormones (melaninstimulating hormones $\alpha-, \beta-, \gamma$-MSHs and the adrenocorticotropic hormone ACTH) that trigger the production of melanin pigments when binding to the melanocortin 1-receptor (MC1R) and other physiological and behavioral functions when binding to four other melanocortin receptors (MC2-5Rs). Through binding to MC1R, MC3R, and MC5R, melanocortins, as well as the $\alpha-\mathrm{MSH}$-derived products reduce acute, allergic and systemic inflammation and septic shock (reviewed by Ducrest et al., 2008; Catania et al., 2010). In addition, activation of MC1R causes a collective reduction in the pro-inflammatory cytokines and prostaglandins and an increase in the anti-inflammatory mediators involved in the inflammatory process (reviewed in Gangoso et al., 2011).

Under both mechanisms, one would predict enhanced inflammatory responses in paler, less-eumelanotic individuals which has indeed been unambiguously established in at least one avian species [(Gangoso et al., 2011) but see (Jacquin et al., 2011)]. Inflammation, leading to terminal septicemia is a typical hallmark of Trichomonas gallinae infection (e.g., Neimanis et al., 2010), so one might hypothesize that paler greenfinches (i.e., the ones with suppressed expression of genes involved in eumelanin production) were more likely to die due to their over-responsive inflammatory defenses. For instance, tissue swelling is an inherent part of inflammatory reaction and death in avian trichomonosis usually occurs from starvation or asphyxiation, as a result of inflammatory lesions blocking oesophageal and/or tracheal openings (e.g., Bunbury et al., 2008). One might thus speculate that better control over inflammatory cascades (e.g., by production of anti-inflammatory cytokines) would result in milder pathogenicity in avian trichomonosis.

Another possible mechanism linking melanin-based plumage coloration to trichomonosis-induced mortality relates to pleiotropic covariation between melanin production and stress 
susceptibility. Association between melanin-based pigmentation and behavioral-physiological aspects of animal personality appears to be widespread in vertebrates, with more distinctly pigmented individuals typically being more proactive, stressresistant, and socially dominant (reviewed by Kittilsen et al., 2009, 2012). It may thus appear possible that greenfinches with paler eumelanic tail coloration appeared more susceptible to stress associated with being brought into captivity than their darker conspecifics. Stress-induced immune suppression would make pale individuals more susceptible to trichomonosis. Higher stress-susceptibility of pale greenfinches is consistent with significantly paler plumage coloration among birds with fault bars. These two alternative scenarios (inflammation-induced mortality vs. stress-induced susceptibility) can be experimentally distinguished by administration of glucocorticoids or other antiinflammatory substances to experimentally or naturally infected individuals. Further, under the latter scenario one would predict negative correlations between eumelanin-based coloration and various markers of stress susceptibility, such as feather and blood corticosterone levels, heterophil hemoconcentration and different behavioral measures of captivity intolerance. Indeed data on blood corticosterone responses from barn owls (reviewed by Roulin and Ducrest, 2011) and barn swallows (Saino et al., 2013a) are consistent with such predictions.

\section{CONCLUDING REMARKS}

We demonstrated an extremely strong directional selection on melanin-based plumage coloration, exerted by an emerging infectious disease. This finding exemplifies the enormous importance of parasites as agents of natural selection in the wild. The major limitation of the current study was our inability to establish infection status of survivors. This issue has to be addressed in future studies by applying molecular diagnostic tools. Importantly, our results suggest that melanin-based coloration can evolve via mechanisms that are independent of visual information provided by the pigment. This idea is relevant for understanding the mechanisms of evolution of melanin-based coloration in general. So far, the research in this area has been mainly concentrating on finding the costs of melanin-based display (McGraw, 2006b). We suggest that the possibility that melanin-based integument coloration can evolve as a by-product of selection on pleiotropically linked physiological traits (see also Bize et al., 2006) deserves serious consideration in future studies.

\section{ACKNOWLEDGMENTS}

We thank Ulvi Karu, Tuul Sepp, Richard Meitern and Mari-Ann Lind for the help with the bird catching and maintenance. Two anonymous reviewers provided constructive criticism on the ms. The study was financed by the Estonian Ministry of Education and Science (target-financing project \# 0180004s09) and by the European Union through the European Regional Development Fund (Centre of Excellence Frontiers In Biodiversity Research).

\section{SUPPLEMENTARY MATERIAL}

The Supplementary Material for this article can be found online at: http://journal.frontiersin.org/Journal/10.3389/fevo.2014. 00004/abstract

\section{REFERENCES}

Atkinson, C. T., Thomas, N. J., and Hunter, D. B. (2008). Parasitic Diseases of Wild Birds. Singapore: Wiley Online Library. doi :10.1002/97808138 04620

Bize, P., Gasparini, J., Klopfenstein, A., Altwegg, R., and Roulin, A. (2006). Melaninbased coloration is a nondirectionally selected sex-specific signal of offspring development in the alpine swift. Evolution 60, 2370-2380. doi: 10.1111/j.00143820.2006.tb01871.x

Bortolotti, G. R. (2006). "Natural selection and coloration: protection, concealment, advertisement, or deception," in Bird Coloration, eds G. E. Hill and K. J. McGraw (Cambridge, MA: Harvard University Press), $3-35$.

Bortolotti, G. R., Dawson, R. D., and Murza, G. L. (2002). Stress during feather development predicts fitness potential. J. Anim. Ecol. 71, 333-342. doi: 10.1046/j.1365-2656.2002.00602.x

Bunbury N., Jones C. G., Greenwood A. G., and Bell D. J. (2008). Epidemiology and conservation implications of Trichomonas gallinae infection in the endangered Mauritian pink pigeon. Biol. Conserv. 141, 153-161 doi: 10.1016/j.biocon.2007.09.008

Catania, A., Lonati, C., Sordi, A., Carlin, A., Leonardi, P., and Gatti, S. (2010). The melanocortin system in control of inflammation. Sci. World J. 10, 1840-1853. doi: 10.1100/tsw.2010.173

Cramp, P., and Perrins, C. M. (1994). The Birds of Western Palearctic. Oxford: Oxford University Press.

Desrochers, D. W., Reed, J. M., Awerman, J., Kluge, J. A., Wilkinson, J., Van Griethuijsen, L. I., et al. (2009). Exogenous and endogenous corticosterone alter feather quality. Comp. Biochem. Physiol. A Mol. Integr. Physiol. 152, 46-52. doi: 10.1016/j.cbpa.2008.08.034

Ducrest, A. L., Keller, L., and Roulin, A. (2008). Pleiotropy in the melanocortin system, coloration and behavioural syndromes. Trends Ecol. Evol. 23, 502-510. doi: 10.1016/j.tree.2008.06.001

Gangoso, L., Grande, J. M., Ducrest, A. L., Figuerola, J., Bortolotti, G. R., Andres, J. A., et al. (2011). MC1R-dependent, melanin-based colour polymorphism is associated with cell-mediated response in the Eleonora's falcon. J. Evol. Biol. 24, 2055-2063. doi: 10.1111/j.1420-9101.2011.02336.x

Graham, A. L., Allen, J. E., and Read, A. F. (2005). Evolutionary causes and consequences of immunopathology. Ann. Rev. Ecol. Evol. Syst. 36, 373-397. doi: 10.1146/annurev.ecolsys.36.102003.152622

Hamilton, W. D., and Zuk, M. (1982). Heritable true fitness and bright birds: a role of parasites. Science 218, 384-387. doi: 10.1126/science.7123238

Hill, G. E. (2006). "Environmental regulation of ornamental coloration," in Bird Coloration., Vol. I. Mechanisms and Measurements, eds G. E. Hill and K. J. McGraw (Cambridge, MA: Harvard University Press), 507-560.

Hill, G. E., and Farmer, K. L. (2005). Carotenoid-based plumage coloration predicts resistance to a novel parasite in the house finch. Naturwissenschaften 92, 30-34. doi: 10.1007/s00114-004-0582-0

Hill, G. E., and McGraw, K. J. (2006). Bird Coloration, Vol. II. Function and Evolution. Cambridge, MA: Harvard University Press.

Hõrak, P., Männiste, M., Meitern, R., Sild, E., Saks, L., and Sepp, T. (2013). Dexamethasone inhibits corticosterone deposition in feathers of greenfinches. Gen. Comp. Endocrinol. 191, 210-214. doi: 10.1016/j.ygcen.2013.07.002

Hõrak, P., Sild, E., Soomets, U., Sepp, T., and Kilk, K. (2010). Oxidative stress and information content of black and yellow plumage coloration: an experiment with greenfinches. J. Exp. Biol. 213, 2225-2233. doi: 10.1242/jeb. 042085

Jacquin, L., Haussy, C., Bertin, C., Laroucau, K., and Gasparini, J. (2013). Darker female pigeons transmit more specific antibodies to their eggs than do paler ones. Biol. J. Linn. Soc. 108, 647-657. doi: 10.1111/bij.12001

Jacquin, L., Lenouvel, P., Haussy, C., Ducatez, S., and Gasparini, J. (2011). Melaninbased coloration is related to parasite intensity and cellular immune response in an urban free living bird: the feral pigeon Columba livia. J. Avian Biol. 42, 11-15. doi: 10.1111/j.1600-048X.2010.05120.x

Jennions, M. D., Møller, A. P., and Petrie, M. (2001). Sexually selected traits and adult survival: a meta-analysis. Q. Rev. Biol. 76, 3-36. doi: 10.1086/393743

Keyser, A. J., and Siefferman, L. M. (2005). Viability selection against highly ornamented males. Evol. Ecol. Res. 7, 595.

Kittilsen, S., Johansen, I. B., Braastad, B. O., and Øverli, Ø. (2012). Pigments, parasites and personalitiy: towards a unifying role for steroid hormones? PLoS ONE 7:e34281. doi: 10.1371/journal.pone.0034281 
Kittilsen, S., Schjolden, J., Beitnes-Johansen, I., Shaw, J. C., Pottinger, T. G., Sørensen, C., et al. (2009). Melanin-based skin spots reflect stress responsiveness in salmonid fish. Horm. Behav. 56, 292-298. doi: 10.1016/j.yhbeh.2009.06.006

Lehikoinen, A., Lehikoinen, E., Valkama, J., Väisänen, R. A., and Isomursu, M. (2013). Impacts of trichomonosis epidemics on Greenfinch Chloris chloris and Chaffinch Fringilla coelebs populations in Finland. Ibis 155, 357-366. doi: 10.1111/ibi.12028

Lindström, K., and Lundström, J. (2000). Male greenfinches (Carduelis chloris) with brighter ornaments have higher virus infection clearance rate. Behav. Ecol. Sociobiol. 48, 44-51. doi: 10.1007/s002650000217

Lochmiller, R. L., and Deerenberg, C. (2000). Trade-offs in evolutionary immunology: just what is the cost of immunity? Oikos 88, 87-98. doi: 10.1034/j.16000706.2000.880110.x

Lozano, G. A. (1994). Carotenoids, parasites and sexual selection. Oikos 70, 309-311. doi: 10.2307/3545643

Männiste, M., and Hõrak, P. (2011). Effects of immune activation and glucocorticoid administration on feather growth in greenfinches. J. Exp. Zool. A Ecol. Genet. Physiol. 315, 527-535. doi: 10.1002/jez.701

McGraw, K. J. (2006a). "Mechanics of carotenoid-based coloration," in Bird Coloration. Mechanisms and Measurements, eds G. E. Hill and K. J. McGraw (Cambridge, MA: Harvard University Press), 177-242.

McGraw, K. J. (2006b). "Mechanics of melanin-based coloration," in Bird Coloration. Mechanisms and Measurements, eds G. E. Hill and K. J. McGraw (Cambridge, MA: Harvard University Press), 243-294.

McGraw, K. J. (2008). An update on the honesty of melanin-based color signals in birds. Pigment Cell Melanoma Res. 21, 133-138. doi: 10.1111/j.1755148X.2008.00454.x

Møller, A. P., and Erritzøe, J. (2000). Predation against birds with low immunocompetence. Oecologia 122, 500-504. doi: 10.1007/s004420050972

Møller, A. P., Erritzøe, J., and Nielsen, J. T. (2009). Frequency of fault bars in feathers of birds and susceptibility to predation. Biol. J. Linn. Soc. 97, 334-345. doi: 10.1111/j.1095-8312.2009.01204.x

Moreno, J., and Møller, A. (2006). Are melanin ornaments signals of antioxidant and immune capacity in birds. Acta Zool. Sinica 52, 202-208.

Moret, Y., and Schmid-Hempel, P. (2000). Survival for immunity: the price of immune system activation for bumblebee workers. Science 290, 1166-1168. doi: 10.1126/science.290.5494.1166

Neimanis, A. S., Handeland, K., Isomursu, M., Agren, E., Mattsson, R., Hamnes, I. S., et al. (2010). First report of epizootic trichomoniasis in wild finches (Family Fringillidae) in Southern Fennoscandia. Avian Dis. 54, 136-141. doi: 10.1637/8952-060509-Case.1

Nolan, P. M., Hill, G. E., and Stoehr, A. M. (1998). Sex, size and plumage redness predict house finch survival in an epidemic. Proc. R. Soc. Lond. B Biol. Sci. 265, 961-965. doi: 10.1098/rspb.1998.0384

Robinson, R. A., Lawson, B., Toms, M. P., Peck, K. M., Kirkwood, J. K., Chantrey, J., et al. (2010). Emerging infectious disease leads to rapid population declines of common british birds. PLOS ONE 5:e12215. doi: 10.1371/journal.pone.0012215
Roulin, A., and Altwegg, R. (2007). Breeding rate is associated with pheomelanism in male and with eumelanism in female barn owls. Behav. Ecol. 18, 563-570. doi: 10.1093/beheco/arm015

Roulin, A., and Ducrest, A.-L. (2011). Association between melanism, physiology and behaviour: a role for the melanocortin system. Eur. J. Pharmacol. 660, 226-233. doi: 10.1016/j.ejphar.2011.01.036

Saino, N., Canova, L., Costanzo, A., Rubolini, D., Roulin, A., and Møller, A. P. (2013a). Immune and stress responses covary with melanin-based coloration in the barn swallow. Evol. Biol. 40, 521-531. doi: 10.1007/s11692-013-9228-5

Saino, N., Romano, M., Rubolini, D., Ambrosini, R., Caprioli, M., Milzani, A., et al. (2013b). Viability is associated with melanin-based coloration in the barn swallow (Hirundo rustica). PLoS ONE 8:e60426. doi: 10.1371/journal.pone.0060426

Saino, N., Romano, M., Rubolini, D., Teplitsky, C., Ambrosini, R., Caprioli, M., et al. (2013c). Sexual dimorphism in melanin pigmentation, feather coloration and its heritability in the barn swallow (Hirundo rustica). PLoS ONE 8:e58024. doi: 10.1371/journal.pone.0058024

Simons, M. J. P., Cohen, A. A., and Verhulst, S. (2012). What does carotenoiddependent coloration tell? Plasma carotenoid level signals immunocompetence and oxidative stress state in birds? A meta-analysis. PLoS ONE 7:e43088. doi: 10.1371/journal.pone. 0043088

Svensson, L. (1992). Identification Guide to European Passerines. Stockholm: L. Svensson.

Svensson, P., and Wong, B. (2011). Carotenoid-based signals in behavioural ecology: a review. Behaviour 148, 131-189. doi: 10.1163/000579510X548673

Van Oort, H., and Dawson, R. D. (2005). Carotenoid ornamentation of adult male common redpolls predicts probability of dying in a salmonellosis outbreak. Funct. Ecol. 19, 822-827. doi: 10.1111/j.1365-2435.2005.01035.x

Walker, L. K., Stevens, M., Karadas, F., Kilner, R. M., and Ewen, J. G. (2013). A window on the past: male ornamental plumage reveals the quality of their early-life environment. Proc. Biol. Sci. 280. doi: 10.1098/rspb.2012.2852

Conflict of Interest Statement: The authors declare that the research was conducted in the absence of any commercial or financial relationships that could be construed as a potential conflict of interest.

Received: 23 December 2013; accepted: 17 February 2014; published online: 06 March 2014.

Citation: Männiste M and Hõrak P (2014) Emerging infectious disease selects for darker plumage coloration in greenfinches. Front. Ecol. Evol. 2:4. doi: 10.3389/fevo. 2014.00004

This article was submitted to Behavioral and Evolutionary Ecology, a section of the journal Frontiers in Ecology and Evolution.

Copyright (C) 2014 Männiste and Hörak. This is an open-access article distributed under the terms of the Creative Commons Attribution License (CC BY). The use, distribution or reproduction in other forums is permitted, provided the original author(s) or licensor are credited and that the original publication in this journal is cited, in accordance with accepted academic practice. No use, distribution or reproduction is permitted which does not comply with these terms. 